\title{
THE PHENOMENON OF ZIKIR SAMAN IN BONJEROK VILLAGE- JONGGAT, CENTRAL LOMBOK, WEST NUSA TENGGARA
}

\author{
Muhammad Atiq \\ Pasca Sarjana, UIN Sunan Kalijaga, Yogyakarta \\ atiqmuhammad975@gmail.com
}

\begin{abstract}
This article will discuss the tradition of recitation of zikr Saman in Bonjeruk Village, Central Lombok West Nusa Tenggara. By photographing the phenomenon of the Zikir Saman, this article will review how Zikir Saman implemented in the society by being inspired by hadith texts and along with its acculturation to local culture. By using the living Hadith lens, this research goes through the stages of observation, interview, documentation and interpretation. The identification of problems in this reserach includes: a brief history and development of the zikr saman in Bonjeruk Village, the form of performance and its function in the muslim society. The findings of this study are: First, the tradition of Zikir Saman in Bonjeruk Village has sanad connection to Zikir Saman in Banten which was initiated by Shaykh Abdul Karim. Second, the zikir Saman in Bonjeruk Village experiences dynamics from time to time: from sacred rituals ferformance to profane entertainment show, zikir Saman staged in tourism events. Third, the recitation of Zikr Saman in Bonjeruk Village was a tradition inherent in the aristocracy habitus, because the first bearer of this tradition was Raden Hukum (Datu/King Jonggat). But later, this tradition developed into a folk tradition that most people are interested in.
\end{abstract}

Keywords: Zikir Saman, Sasak and Living Hadis.

\section{FENOMENA ZIKIR SAMAN DI DESA BONJEROK KECAMATAN JONGGAT, LOMBOK TENGAH, NUSA TENGGARA BARAT}

\begin{abstract}
Abstrak - Artikel ini akan membahas tradisi Zikir Saman di Desa Bonjeruk Lombok Tengah dengan menggunakan kerangka living Hadis. Dengan memotret fenomena Zikir Saman tersebut, artikel ini akan mengulas bagaimana Zikir Saman diimplementasikan dalam kehidupan masyarakat dengan yang diinspirasi dari teksteks hadis dan dengan segenap akulturasinya dengan budaya setempat. Melalui pendekatan Living Hadis penelitian ini melewati tahapan observasi,wawancara, dokumentasi dan interpretasi. Adapun Identifikasi masalah dalam penelitian ini meliputi: sejarah singkat dan perkembangan zikir saman di Desa Bonjeruk, bentuk performa dan fungsinya. Temuan penelitian ini adalah: Pertama, bahwa tradisi Zikir Saman di Desa Bonjeruk memiliki ketersambungan sanad dengan tradisi Zikir Saman Banten, Syaikh Abdul Karim. Kedua, bazikir Saman di Desa Bonjeruk mengalami dinamika dari waktu ke waktu. Misalnya, dari ritual sakral menjadi hiburan-profan, yakni Zikir Saman dipentaskan dalam even even wisata. Ketiga, Zikir Saman di Desa Bonjeruk merupakan tradisi yang melekat dengan kalangan bangsawan, karena pembawa tradisi ini pertama kali adalah bagsawan sasak Raden Hukum (Datu Jonggat). Namun kemudian, tradisi ini berkembang menjadi tradisi rakyat yang diminati oleh sebagian besar masyarakat.

Kata kunci: Zikir Saman, Sasak dan Living Hadis.
\end{abstract}




\section{Pendahuluan}

Zikir Saman dan Tari Saman merupakan dua hal yang identik, namun belakangan menjadi dua hal yang agak berlainan. Membincangkan zikir Saman misalnya, maka selalu identik dengan kesenian zikir masyarakat Banten. Sedangkan membincangkan tarian saman akan lebih identik dengan kultur masyarakat Aceh. Kesenian zikir Saman diyakini telah dipopulerkan oleh para ulama dan Sultan Banten pada abad ke-18. Kemudian disebarkan ke luar Banten oleh sosok yang disebut Ki Sarimi. Ia menyebarkan kesenian ini di daerah Wanagiri Kabupaten Lebak, berdekatan dengan Desa Ciandur. Keterampilan ini kemudian diwariskan kepada Ki Dasik, yang selanjutnya diwariskan lagi kepada Ki Nirman, Ki Jasman, Ki Sarka Apandi, dan Ki Surahman. ${ }^{1}$

Sementara itu, tarian saman Aceh, yang tumbuh di Gayo, belakangan ini telah ditetapkan menjadi warisan dunia tak benda oleh UNESCO pada 24 November 2011. ${ }^{2}$ Gerakan tarian tradisional ini menyuguhkan harmonisasi dan sinergisitas dari para penarinya. Sebab melalui tarian tersebut masyarakat menujukkan sebuah ungkapan kultur, spiritualitas dan sejarah. Namun demikian, ketika membincangkan zikir Saman, kesenian zikir Saman dibawa oleh para ulama dan Sultan Banten pada abad ke 18. Pada periode selanjutnya yakni di wilayah daerah Banten dikenal seorang tokoh yang diyakini sebagai penyebar kesenian ini yang bernama Ki Sarimi. Ia menyebarkan kesenian ini di daerah Wanagiri Kabupaten Lebak, berdekatan dengan Desa Ciandur. Keterampilan ini kemudian diwariskan kepada Ki Dasik, yang selanjutnya diwariskan lagi kepada Ki Nirman, Ki Jasman, Ki Sarka Apandi, dan Ki Surahman.

Sedangkan Tari Saman Aceh merupakan sebuah tarian asal Suku Gayo, yang diklaiam mulai berkembang sejak abad ke 14, dan dipelopori oleh seorang ulama besar bernama Syekh Saman. Konon, tarian ini awalnya hanyalah sebuah permainan rakyat bernama Pok Ane. Lalu masuknya Islam ke daerah Gayo pada masa itu memunculkan berakulturasi dengan budaya setempat, yakni permainan Pok Ane. Kemudian nyanyian pengiring permainan Pok Ane diubah dengan pujian-pujian kepada Allah. Kehadiran Islam juga turut mengubah beberapa gerakan pada tari saman mulai dari tepukan dan perubahan tempat duduk. Tari saman di masa Kesultanan Aceh hanya ditampilkan pada acara perayaan Maulid Nabi Muhammad di surau-surau atau masjid di daerah Gayo, namun pada perkembangannya ia juga kemudian dimainkan pada acara-acara umum seperti acara pesta ulang tahun, pernikahan, khitan, dan acara lainnya hingga sekarang. ${ }^{3}$

Terlepas dari perbedaan konteks historis dan perspektif di atas, artikel ini akan coba membahas fenomena Zikir Saman yang masih eksis di lingkungan masyarakat Muslim Sasak, tepatnya di Desa Bonjeruk kecamatan Jonggat kabupaten Lombok Tengah Nusa Tenggara Barat. Artikel ini akan membahas Zikir Saman ini dengan

\footnotetext{
${ }^{1}$ https://koranbanten.com/kesenian-dzikir-saman-khas-pandeglang/, diakses pada tanggal 14 September 2020 pada pukul 17.25 WITA.

2 https://kumparan.com/acehkini/tarian-saman-awalnya-misi-dakwah-hingga-jadi-warisandunia-lrijNOEYklZ, diakses pada tanggal 14 September 2020 pukul 17.00 WITA WITA

${ }^{3}$ http://abulyatama.ac.id/?p=5267, diakses pada tanggal 14 September 2020 pada pukul 20.00
} 
kerangka Living Hadis, yakni meneropong landasan-landasan normatif dari teks hadis yang menjadi acuan praktik tersebut dalam artikulasi budaya dan kearifan lokal setempat.

Kajian terhadap zikir zaman sebagai sebuah fenomena sosial budaya masayarakat Islam (Islamic Societies) menjadi obyek kajian riset sosial, termausk riset mengenai living hadits. Ada beberapa tulisan yang mengarahkan fokus ke titik kajian itu. Atrin meneliti zikir zaman sebagai sebuah seni tradisi (esthetic tradition) di Provinsi Banten. Ia melihat bahwa zikir zaman sebagai sebuah fetomena seni yang memiliki makna tersendiri bagi masyarakat pelakunya, ia mengkategorikan zikir zaman sebagai sebuah seni pertunjukan yang memiliki makna spiritual, hiburan dan estetis. ${ }^{4}$ Lokalitas sangat menentukan makna bagi sebuah tradisi seni. Penelitian Asbullah Muslim juga mengambil fokus zikir saman, dengan lokus penelitian Lombok Timur, menggunakan kerangka studi etnopedagogi -identifikasi core values sebuah kebudayaan lokal.

Kajian ini menyimpulkan bahwa praktek zikir Saman di Lombok Timur identik dengan Tarekat Samaniyah, karena perbuatan dan lagunya sama dengan apa yang diajarkan Muhammad As-Saman, hanya kemudian diakulturasikan dengan budaya Lombok, Saman merupakan majlis zikir yang bertujuan untuk mendekatkan diri kepada Allah swt, karena syair-syair yang dibaca dalam zikir Saman terdiri dari shalawat dan kalimat tauhid. Zikir Saman merupakan tradisi religius, yang berfungsi bukan hanya sebagai majlis zikir, tetapi sekaligus berfungsi sebagai hiburan kesenian masyarakat. ${ }^{5}$ Penelitian lain yang juga senada adalah Ela Hikmah yang dipublish di jurnal Lektur juga menarasikan eksistensi zikir saman yang sama. Ekspresi zikir saman tersebut merupakan bentuk perpaduan dari unsur nilai agama Islam dan budaya lokal. Keberadaan seni Zikir Saman berfungsi sebagai media komunikasi antar individu di daerah Pandeglang, yang nantinya mampu menjadi suatu budaya masyarakat yang dapat mempererat tali silaturahmi. ${ }^{6}$

Kajian yang penulis lakukan ini juga merupakan ritme penelitain yang sama, hanya saja ada fokus yang berbeda dalam kerangka kajian, penulis menggunakan kerangka kajian living hadits. Zikir saman merupakan fenomena tradisi sosial-budayakeagamaan, dan tergolong tarian spiritual atau bisa juga disebut sebagai gerakan spritual art yang penulis kaji di Lombok Tengah. Penulis melihat fenomena atau tradisi ini merupakan fenomena living hadis, sebab praktik semisal ini memiliki landasan hadits Nabi sebagaimana praktik religious lainnya, semisal: barzanji, shalawan dan lainnya. Zikir saman juga dapat dilihat sebagai gerakan sosial keagamaan masyarakat yang ingin menyampaiakan nilai-nilai kecintaan kepada Nabi melalui shalawat, melalui seni yang Islami. Inilah yang menjadi fokus kajian penulis.

\footnotetext{
${ }^{4}$ Artin Suryatin, "Seni Zikir Zaman di Desa Ciandur Kabuapaten Pnandegelang Banten" dalam Jurnal Pendidikan Seni Tari, 2014, 5-7.

${ }^{5}$ Asbullah Muslim "Studi Etnopedagogi dalam Praktik Zikir Saman di Lombok Timur”, dalam Jurnal Studi Agama dan Masyarakat, Vol. 14, No 02, Desember 2018, 114-115

${ }^{6}$ Ela Hikmah Hayati dan Rasikin "Peran Seni Tari Zikir Saman di Pandeglang, Banten" dalam JurnalLektur Keagamaan, Vol. 17, No. 1, 2019, 99-112
} 


\section{Metode Penelitian}

Studi ini lebih merupakan studi lapangan dengan menggunakan kerangka disiplin Living Hadis. Data dalam penelitian ini diambil dari berbagai sumber seperti melalui kajian observasi, dokumen dan wawancara. Kemudian data-data tersebut dianalisis sesuai dengan konteks Zikir Saman di Desa Bonjeruk Lombok Tengah. Untuk menunjang sumber data dan analisis, penelitian ini juga menggunakan sumber seperti buku-buku dan artikel. Dengan demikian, proses studi ini meliputi penelaahan dokumen dan bahan pustaka, observasi lapangan, analisis, dan interpretasi.

Analisis dan sintesis data dilakukan sejak peneliti melakukan pengumpulan data dari awal. Semua data yang sudah didapat kemudian dibandingkan dengan data yang didapat dari informan yang berbeda, untuk selanjutnya digunakan untuk menggali informasi lebih lanjut dalam wawancara berikutnya. Tahap selanjutnya adalah menganalisis, menyaring menggolongkan dan mengambil kesimpulan dari data yang sudah ada, kemudian tahap terakhir adalah menyajikan dalam sebuah kerangka living hadis. Perspektif living hadis ini akan berfungsi sebagai tool analysis tentang masyarakat, sistem sosial yang berkaitan dengan tradisi zikir Saman. Dengan demikian akan dapat dipahami keseluruhan sistem sosial tata budaya dan proses pelestarian zikir saman di desa Bonjeruk tersebut.

\section{Hasil Penelitian dan Pembahasan \\ Profil Desa Bonjeruk}

Desa Bonjeruk Kecamatan Jonggat, Kabupaten Lombok Tengah, Nusa Tenggara Barat (NTB) ${ }^{7}$ kini merupakan salah satu desa wisata. ${ }^{8}$ Desa ini termasuk desa tua, dahulu desa ini adalah pusat pemerintahan tingkat Distrik Jonggat. Karenanya, di sana bisa dilihat adanya bangunan bekas kantor Distrik Jonggat dan tempat kediamannya yang bercirikan bangunan Belanda. Dari kota Mataram menuju Bonjeruk sekitar 20 kilometer ke arah tenggara atau memerlukan waktu sekitar kurang lebih 45 menit.

Menurut Lalu Putrie, Kepala Dinas Pariwisata Kabupaten Lombok Tengah, Bonjeruk merupakan salah satu desa tertua di Lombok Tengah. Desa Bonjeruk berdiri tahun 1886. Keberadaannya sebenarnya sudah ada sejak 1852. Sedangkan, Menurut Wira Jaya Putra Lalu Adi Permadi, Bonjeruk dari sejarahnya sebagai ibu kota Kerajaan Jonggat, yang didirikan oleh para keturunan Datu Pujut di Pampang. Kedatuan Jonggat adalah pecahan dari Pujut yang kemudian mandiri dan membangun kerajaan sendiri.

Selain itu, Desa Bonjeruk juga menyimpan jejak kolonialisme Belanda. Ada beberapa bangunan dengan desain art deco peninggalan Belanda. Desa Bonjeruk sendiri pernah menjadi pusat administrasi kolonial. Tidak mengherankan jika terdapat beberapa bangunan bergaya Eropa di desa tersebut. Salah satu bangunan tersebut yaitu gapura berwarna krem. Terdapat tulisan 'Bondjeroek den 10 mei' dengan angka tahun

7 https://id.wikipedia.org/wiki/Bonjeruk,_Jonggat,_Lombok_Tengah, diakses pada tanggal 20 september 2020 pada pukul 09.10 WITA.

8 https://www.disbudpar.ntbprov.go.id/yuk-kenali-desa-wisata-bonjeruk/, diakses pada tanggal 7 Oktober 2020 pada pukul 09.26 WITA. 
1933. Bangunan ini didirikan pada 1933, sebagai gerbang masuk menuju komplek perumahan era Belanda. Tidak jauh dari bangunan itu, berdiri Masjid Raden Nunu Unas. Masjid ini juga menggunakan gaya arsitektur art deco lantaran dibangun sejak zaman Belanda. Keberadaan bangunan peninggalan Belanda tersebut menjadi daya tarik tersendiri bagi Desa Bonjeruk. Sebagai tujuan wisata, desa ini menghadirkan perpaduan sejarah dengan budaya yang kental sekaligus pemandangan alam yang asri.

Nama desa Bonjeruk berasal dari nama pohon jeruk tempat ditemukannya sebuah sumur. Di masa lampau, di desa Bonjeruk berdiri kerajaan Jonggat. Salah satu raja atau Datu yang terkenal dari kerajaan ini bernama Raden Nune Emas. Nama ini kemudian diabadikan menjadi nama sebuah masjid di desa Bonjeruk. Menurut kepala Bidang Pemasaran dan Promosi Dinas Pariwisata Kabupaten Lombok Tengah L. M. Zulfa Halim, pamerintah kabupaten sangat berkepentingan mempromosikan Desa Wisata sejarah Bonjeruk mengingat desa ini sangat potensial untuk dikembangkan dari berbagai sudut, baik dari sudut arsitektural, tata ruang, peninggalan sejarah dan budaya. Oleh karena itu L.M. Zulfa Halim mengangkat Gerbang Tua di Gedeng Beleq Bonjeruk sebagai salah satu icon pariwisata Lombok Tengah yang dicantumkan dalam booklet pariwisata Lombok Tengah. ${ }^{9}$

Desa Bonjeruk terdiri dari 14 dusun. Seiring dengan perkembangan wisata di Lombok, desa ini dikembangakn mejadi desa wisata, dan hampir semua dusun tersebut memiliki potensi wisata. Bonjeruk Permai, Presak dan Batu Jering adalah dusn superprioritas. Sedangkan Dusun Bonjeruk Duah, Bonjeruk Dalem, Bat Pekan Timuk, dan Loang Tune juga sedang dikembangkan.

\section{Praktik dan Ritual Zikir Saman di Desa Bonjeruk Sejarah Singkat}

Zikir Saman merupakan sebuah tradisi yang sampai sekarang masih sering dilaksanakan oleh masyarakat Lombok. Terdapat beberapa perbedaan sudut pandang mengenai zikir Saman. Sebagian masyarakat berpandangan bahwa Saman merupakan majlis zikir yang bertujuan untuk mendekatkan diri kepada Allah swt, karena syairsyair yang dibaca dalam zikir Saman terdiri dari shalawat dan kalimat tauhid. Sebagian masyarakat yang lain berpandangan bahwa zikir Saman merupakan tradisi religius, yang berfungsi bukan hanya sebagai majlis zikir, tetapi sekaligus berfungsi sebagai hiburan kesenian masyarakat. Ada pula masyarakat yang memandang bahwa zikir Saman sebagai tarekat, meskipun tidak memiliki guru yang jelas, sebagaimana tarekattarekat yang lain. ${ }^{10}$

Tradisi zikir saman di desa Bonjeruk ini telah ada sejak lama. Menurut informan, bahwa tradisi ini dibawa oleh Raden Hukum, bangsawan Jonggat sekaligus tokoh agama. Raden hukum mendapat ijazah zikir saman ini melalui jalur Tuan Guru Muhammad Arifin Mesangok, Lombok Barat, Syaikh Usman Serawak Malaysia,

${ }^{9}$ Lalu Adi Permadi, GA Sri Oktariyani, Iwan Kusuma Negara, Siti Sofiyah, Abdul Manan, "Peningkatan Kinerja Organisasi Kelompok Sadar Wisata di Desa Bonjeruk, Kecamatan Jonggat, Kbupaten Lombok Tengah", Jurnal Pepadu vol. 1. No. 1, Januari 2020.

${ }^{10}$ Wawancara dengan Gede Muhammad Amin (Senin, 9 Maret, pukul 08.00 Wita) 
Syaikh Abdul Karim Banten, Syaikah Ahmad hotib Sambas. ${ }^{11}$ Tradisi Dzikir Saman ini terus dirawat turun temurun oleh masyakarakat hingga kini. Tradisi ini telah menjadi bagian kultural dalam keberIslaman masyarakat Bonjeruk. Di Desa Bonjeruk sendiri kini terdapat tujuh kelompok Zikir Saman, masing-masing kelompok terdiri dari 35 orang. Pertunjukan ritual ini dilaksanakan pada upacara seperti: Maulid, nikah, haji, khitan, dan uniknya juga dirayakan dalam rangka memperingati hari kemerdekaan indonesia tiap tahunnya. Bahkan lebih dari itu, tradisi ini belakangan mengalami komodifikasi, yakni dipentaskan dalam even-even wisata.

\section{Waktu Pelaksaan dan Bacaan Zikir Saman}

Pertunjukan Seni zikir Saman di Desa Bonjeruk Lombok Tengah dilakukan biasanya pada malam hari, setelah shalat isya, yakni mulai pukul 20.00 sampai dengan pukul 23.00 Wita. Pertunjukan zikir Saman dibagi kedalam tiga tahapan: Tahap pertama dimulai dengan dzikir, seluruh pemain hanya melakukan dzikir dengan khidmat, masing-masing pemain saling berhadapan satu dengan yang lainnya. Tahap kedua, tahapan asroqol, pada bagian ini membaca syair-syair yang mengagungkan Nabi Muhammad SAW yang diambil dari kitab "Berzanji". Tahapan terakhir yaitu tahap saman, pada bagian ini seluruh pemain zikir Saman melakukan joged dengan sesuai dengan irama beluk, karena tahapan ini merupakan bagian hiburan dari pertunjukan Dzikir Saman.

\section{Jenis-Jenis Gerakan}

Seperti umumnya zikir saman, praktik zikir Saman di Desa Bonjeruk juga dilengkapi dengan gerakan-gerakan. Setidaknya, ada dua jenis gerakan yakni: gerakan Nunggal dan gerakan Inti. Gerakan nunggal adalah salah satu praktek zikir Saman yang berbentuk sama', yakni mendengarkan syair-syair yang terdapat di dalam kitab Lu'lu Mansyur. Syair-syair itu dilantunkan dengan penuh irama dan cengkok oleh seorang Hadi (Mursyid). Kemudian dalam waktu bersamaan para jama'ah zikir Saman mendengarkan dengan khidmat sambil menghayati makna dan pesan-pesan dalam syair tersebut. Seorang Hadi dalam gerakan Nunggal ini juga aktif melantunkan beberapa ayat Al-Qur'an dan shalawat Nabi dan doa-doa. Hal ini dijelaskan oleh Abdus Shamad al-palimbani yang kemudian disarikan dari Ratib Saman, dijelaskan bahwa dalam gerakan Nunggal terdapat beberapa amalan zikir dan wirid, yang diawali dengan surah Ad-Dhuha kemudian diakhiri dengan doa-doa. Adapun zikir dan wirid yang dibaca dalam gerakan Nunggal adalah sebagai berikut:

Pertama, membaca Basmallah kemudian dilanjutkan dengan La ila ha illAllah wa Allahu akbar. Kedua, membaca Qureean surah Ad-Dhuha, surah Al-Ikhlas, surah AlFalaq, surah An-Naas, surah Al-Fatihah, surah Al-Baqarah ayat 1-6 dan ayat 255 (ayat kursi). Ketiga, membaca amalan dalam tahlilan (doa tahlil), selanjutnya membaca shalawat dan diakhiri dengan bacaan La haula wa la quwwata illa billah .

\footnotetext{
${ }^{11}$ Wawanacara dengan Lalu Haji Goyatuz Zuhdi (Selasa, 10 Maret 2020, pukul 15.30 Wita)
} 
Terakhir dalam posisi yang sama, tetapi dalam keadaan berhadapan antara dua. Gerakan ini juga diiringi dengan syair-syair (dipimpin oleh seorang Hadi). Syair-syair tersebut antara lain sebagai berikut: Pertama, dimulai dengan lafadz Basmallah, kemudian dilanjutkan dengan lafadz ya hayyu ya qoyyum Laila ha illa anta sebanyak 3 kali. Kedua, membaca istigfar, membaca doa dunia akhirat dan beberapa doa yang lain seperti doa panjang umur serta doa sebelum belajar masing-masing sebanyak tiga kali. Kemudian dilanjutkan dengan membaca Asmaul husna. Keempat, membaca Qurean surah Al-Ikhlas, surah Al-Falaq, surah An-Naas, surah Al-Fatihah dan surah AlBaqarah ayat 1-6. Kelima, membaca syair-syair Allohu rijal, Allohu Majid, Iba dalloh hi rijalalloh, Alloh Jalil, Alloh hayyu, dilanjutkan dengan sholawat badar, dan diakhiri dengan lafadz salam sala man ya baro katu 'ala alfika ya Alloh.

\section{Analisis Living Hadis}

living hadis secara sederhana dapat dimaknai sebagai gejala yang nampak di masyarakat berupa pola-pola perilaku yang bersumber dari hadis Nabi Muhammad Saw. pola-pola perilaku ini merupakan bagian dari respons umat Islam dalam interaksi mereka dengan hadis-hadis Nabi. ${ }^{12}$ Masyarakat Islam semestinya berperilaku sesuai dengan ajaran-ajaran al-Qur'an dan hadis. Akan tetapi, fenomena yang muncul tidak selalu berbanding lurus dengan apa yang semestinya dipraktikkan dan diamalkan. Terdapat juga tradisi atau kebiasaan masyarakat Islam yang dianggap menyimpang, namun masih dapat dilacak landasan normatifnya.

Living hadis adalah kajian atau penelitian ilmiah tentang berbagai peristiwa sosial terkait dengan kehadiran atau keberadaan hadis di sebuah komunitas Muslim tertentu. Dari sana, ditemukan respon sosial (realitas) komunitas Muslim untuk membuat hidup dan menghidupkan teks agama melalui sebuah interaksi yang berkesinambungan. ${ }^{13}$

Setelah melihat data yang diperoleh melalui informan, terlihat bahwa tradisi zikir saman di desa Bonjeruk dipengaruhi oleh faktor alasan normatif. Sebagaimana tradisi zikir Saman yang dilakukan di beberapa daerah di Indonesia pada umumnya, masyarakat di desa Bonjeruk juga melakukan praktik keagamaan ini berlandaskan beberapa dalil. Mereka berangkat dari banyak teks-teks normatif, yaitu yang bersumber dari al-Qur'an dan hadis, di antaranya yaitu: Pertama, dalil al-Qur'an yang menjelaskan tentang berzikir atau mengingat Allah dalam surat Ali Imran ayat 19l:

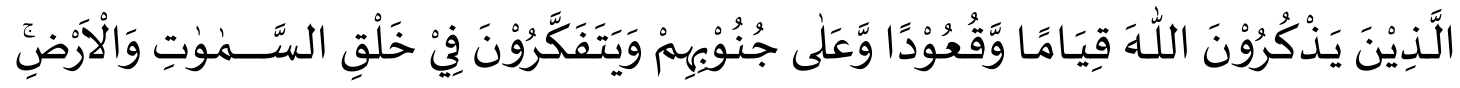

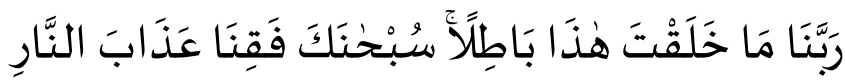

"(yaitu) orang-orang yang mengingat Allah sambil berdiri, duduk atau dalam keadaan berbaring, dan mereka memikirkan tentang penciptaan langit dan bumi (seraya berkata), "Ya

12 Muhammad al-Fatih Suryadilaga, Aplikasi Penelitian Hadis dari Teks ke Konteks (Yogyakarta: Teras, 2009), hlm. 107. 8.

${ }^{13}$ Muh. Mansur, et al., Metodologi Penelitian Living Qur'an dan Hadis (Yogyakarta: Teras, 2007), hlm. 
Tuhan kami, tidaklah Engkau menciptakan semua ini sia-sia; Mahasuci Engkau, lindungilah kami dari azab neraka."

Kedua, ayat al-Qur'an yang menyebutkan apabila seorang hamba mengingat Allah maka Allah akan mengingatnya, dalam surat al-Baqarah ayat 152:

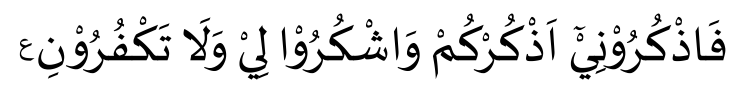

"Maka ingatlah kepada-Ku, Aku pun akan ingat kepadamu. Bersyukurlah kepada-Ku, dan janganlah kamu ingkar kepada-Ku."

Ketiga, hadis yang menyebutkan tanda cinta seorang hamba adalah dengan banyak berzikir.

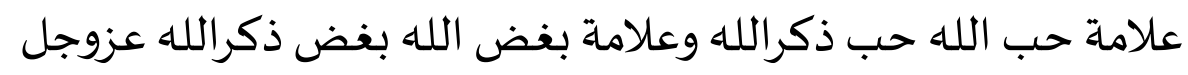

"Tanda kecintaan seorang hamba kepada Allah adalah senang berzikir atau mengingat Allah, dan tanda seorang hamba tidak cinta kepada Allah adalah jarang berzikir atau mengiangat Allah".

Keempat, hadis yang menyebutkan tingginya derajat orang yang banyak berzikir.

$$
\text { أفضيل العباد درجـة عند الله يوم القيامة الذاكرون الله كثيرا }
$$

"Seorang hamba yang paling tinggi derajatnya di sisi Allah pada hari kiamat adalah orang yang paling banyak berzikir kepada Allah". ${ }^{14}$

Berdasarkan beberapa ayat al-Qur'an dan hadis yang menjadi landasannya di atas, masyarakat memahami landasan teks tersebut sebagai perintah dan kewajiban untuk berzikir kepada Allah. Bagi masyarakat, zikir saman dipahami sebagai do'a permohonan. Bagi masyarakat yang akan melaksanakan haji, zikir saman sebagai permohonan kepada Allah agar perjalanan haji lancar dan mendapat haji yang mabrur. Bagi masyarakat yang mengadakan acara khitanan, zikir saman ini sebagai permohonan kepada Allah agar anak yang dikhitan menjadi anak yang alim shalih, dan zikir saman yang dilakukan pada setiap acara 17-an yang bertepatan dengan 17 Agustus sebagai rasa syukur atas kemerdekaan Indonesia serta permohonan do'a agar Indonesia tetap aman.

Transmisi pengetahuan merupakan proses kreatif yang diresepsi agen atas teks al-Qur'an dan hadis sehingga tercipta sebuah praktik tertentu. Proses transmisi pengetahuan dalam tradisi zikir saman diperoleh dari agen utama yaitu Raden Hukum, kemudian meresepsi teks hadis dan teks al-Qur'an kemudian membangun tradisi zikir saman di desa Bonjeruk yang eksis hingga hari ini.

\section{PENUTUP}

14 Muhammad Bin Umar al-Nawawi al-Bantani, Tankih al-Qaul ( Surabaya : Al-Haramaen, 2015),hlm 35. 
Setelah melakukan analisis terhadap keseluruhan data yang diberikan oleh informan, penulis menemukan bahwa, pertama, tradisi Zikir Saman di Desa Bonjeruk memiliki ketersambungan sanad dengan tradisi Zikir Saman Banten, Syaikh Abdul Karim. Kedua, bazikir Saman di Desa Bonjeruk mengalami dinamika dari waktu ke waktu. Misalnya, dari ritual sakral menjadi hiburan-profan, yakni Zikir Saman dipentaskan dalam even even wisata. Ketiga, Zikir Saman di Desa Bonjeruk merupakan tradisi yang melekat dengan kalangan bangsawan, karena pembawa tradisi ini pertama kali adalah bagsawan sasak Raden Hukum (Datu Jonggat). Namun kemudian, tradisi ini berkembang menjadi tradisi rakyat yang diminati oleh sebagian besar masyarakat. 


\section{DAFTAR PUSTAKA}

Al-Bantani, Muhammad Bin Umar al-Nawawi Tankih al-Qaul, Surabaya : Al-Haramaen, 2015.

Hayati, Ela Hikmah dan Rasikin "Peran Seni Tari Zikir Saman di Pandeglang, Banten" dalam Jurnal Lektur Keagamaan, Vol. 17, No. 1, 2019.

Mansur, Muh., et al., Metodologi Penelitian Living Qur'an dan Hadis (Yogyakarta: Teras, 2007.

Muslim, Asbullah, "Studi Etnopedagogi dalam Praktik Zikir Saman di Lombok Timur", dalam Jurnal Studi Agama dan Masyarakat, Vol. 14, No 02, Desember 2018

Permadi, Lalu Adi, GA Sri Oktariyani, Iwan Kusuma Negara, Siti Sofiyah, Abdul Manan, "Peningkatan Kinerja Organisasi Kelompok Sadar Wisata di Desa Bonjeruk, Kecamatan Jonggat, Kbupaten Lombok Tengah”, Jurnal Pepadu vol. 1. No. 1, Januari 2020.

Suryadilaga, Muhammad al-Fatih, Aplikasi Penelitian Hadis dari Teks ke Konteks, Yogyakarta: Teras, 2009.

Suryatin, Artin, "Seni Zikir Zaman di Desa Ciandur Kabuapaten Pnandegelang Banten" dalam Jurnal Pendidikan Seni Tari, 2014.

https://koranbanten.com/kesenian-dzikir-saman-khas-pandeglang/, diakses 14 September 2020.

https://kumparan.com/acehkini/tarian-saman-awalnya-misi-dakwah-hingga-jadi-warisandunia-lrijNOEYklZ, diakses 14 September 2020.

http://abulyatama.ac.id/?p=5267, diakses 14 September 2020.

https://www.disbudpar.ntbprov.go.id/yuk-kenali-desa-wisata-bonjeruk/, diakses pada tanggal 7 Oktober 2020.

https://id.wikipedia.org/wiki/Bonjeruk,_Jonggat,_Lombok_Tengah, diakses pada tanggal 20 September 2020. 